\title{
FESTIVAL PRACTICES IN A VIRTUAL ENVIRONMENT. BENEFITS, PROBLEMS, SUSTAINABILITY
}

\section{Kaloyan Nikolov, kaloyan.nikolov@iefem.bas.bg}

Institute of Ethnology and Folklore Studies with Ethnographic Museum

at the Bulgarian Academy of Science, Sofia, Bulgaria

Abstract: This paper examines the newly emerged practices in organizing festival events with folklore in a virtual environment. Is it possible to introduce information technologies in organizational techniques when conducting them both in a virtual environment and in a hybrid format. Technological solutions for digital fingerprint accumulation. Significance of e-festivals with folklore orientation for communities in safeguarding the intangible cultural heritage.

Keywords: e-Festivals, Intangible Cultural Heritage

\section{ФЕСТИВААНИ ПРАКТИКИ ВЪВ ВИРТУААНА СРЕАА. ПОАЗИ, ПРОБАЕМИ, УСТОЙЧИВОСТ \\ Ка^оян Николов, kaloyan.nikolov@iefem.bas.bg}

Институт по етнология и фролк^ористика с етнографрски музей при Българска акалемия на науките, София, България

Резюме: Настоящата работа разглежАа ново появилите се практики при организирането на фестивални прояви с фолк^орна насоченост във виртуална среда. Възможно ми е въвежАането на информационни технологии в организационните похвати при провежлането им както във виртуална среда, така и в хибрилен формат. Прилагане на технологични решения при акумулирането на Аигитален отпечатък. Значение на е-фестивалите с фолк^орна насоченост за общностите при запазването на нематериалното културно наслеАство. наслеАство

КАючови Ауми: е-феестивали, нематериално културно

Изминалата година на социална Аистанция породена от пандемичната обстановка порали експанзивното разпространение на COVID-19 наложи организаторите на фолк^орни феестивли $\Delta а$ 
предприемат нетипични похвати за провеждането на обявените събития. Чрез използването на напредналите комуникационни технологии, организационните екипи предприеха стьпки за организирането и провежлането на фолклорните прояви във виртуална среда. Съчетаването на технологичните Аостижения с традиционните практики при представянето и оценяването на достиженията на носителите в областта на песенното, танцовото и инструментално тралиционно изкуство полчертано носят нов облик и значение.

ЕАна от основните промени, установени от Конвенцията за опазване на нематериалното културно наслеАство от 2003 г. на ЮНЕСКО (UNESCO, 2003a). е фокусирането на нематериално наслеАство от материално културно наследство. Съществената промяна се индикира С въвежАането на нова концепция за общност („групи И инАивиАи“, цитат от Конвенцията), която преди това е взета предвиА не като активна част за запазване и развитие на културното наследство, а по-скоро като пасивен приемник съобразно Конвенция 1972' (UNESCO, 1972).

В сектора на културното наследство в межАународни организации като ЮНЕСКО и Съвета на Европа вкАЮчат общностите като активни заинтересовани страни в опазването на световното наслеАство И културното многообразие. Въпреки че Конвенцията от 2003 г. не предоставя ясна дефоиниция на „общност, групи и инАивиАи“, тя признава тяхното значение и член 1 изключва съществуването на нематериалното културно наследство при липса на признаване от общностите на сполелено общо наслеАство ${ }^{2}$.

Освен това дьржавите страни по конвенцията трябва Аа ангажират общностите в Аефинирането, идентифрицирането и

1 ЮНЕСКО, Конвенцията за защита на световното културно и природно наслеАство (1972 г.) гласи: Член 5, буква а) „.(...) всяка Аьржава - страна по тази конвенция, ще се стреми, Аоколкото е възможно, и спореА случая за всяка Аьржава : обща политика, която има за цел $\Delta а$ дале на културното и приролно наслеАство функция в живота на общността (...)."

2 ЮНЕСКО, Конвенция (2003): Ч^.1. "Нематериалното културно наследство“ означава практиките, представянията, изразите, знанията, уменията - както и свьрзаните с тях инструменти, предмети, артефакти и културни пространства 
съхраняването на нематериалното културно наследство ${ }^{3}$. През голината след приемането на Конвенция 2003, за да компенсира ^ипсата на ясна Аефриниция за "общност", ЮНЕСКО публикува насоки за прилагане, които преразглежлат тази тема, като заявяват:

„Конвенцията не предоставя определение за общности, тъй като признава, че общностите имат отворен характер, не е зальлжително $\Delta а$ са свързани с конкретни територии. Те могат $\Delta а$ бълат Аоминиращи или неАОминиращи И еАин инАивиА Може Аа принаАлежи еАновременно на различни общности или Аа сменя общности." (UNESCO, 2004), (ЮHECKO, прилагане на Конвенцията за опазване на нематериалното културно наслеАство). ЮНЕСКО не само установи Аефриниция за „общност, група и инАивиАи", но също така се прави граница межАу тези Аица, които „пряко практикуват" и тези, които са "еxternal stakeholders", „външни заинтересовани страни", (UNESCO, 2006). ПослеАно време групата от „заинтересовани страни“ е претьрпяла процес на разширяване благодарение на работата, извьршена от ЮНЕСКО за повишаване на обществения международен интерес по темата, а също и благодарение на инорормационните и комуникационни технологии, които са полезни инструменти за разпространение и популяризиране на нематериалната култура. Основна Аейност в рамките на тази цел е илентифицирането на национални нематериални обекти в сътрудничество с общностите на наслеАството (ЮНЕСКО, 2003, ч^ен 11). Технологичните инструменти са въведени като инструменти за инвентаризиране и отваряне на Аостьпа $\Delta$ о тази инорормация, както и $\Delta$ a ce засили „креативността и самоуважението в общностите и инАивиАите, кьАето произхожАат елементи, изразяване и практики на нематериално културно наслеАство" (UNESCO, 2003b) (ЮНЕCKO, ИАентиорициране и инвентаризиране Нематериално културно наслеАство).

Конвенцията FARO на Съвета на Европа от 2005 г. (COUNCIL OF EUROPE, 2005) също полчертава значението на връзката межлу

З ЮНЕСКО, Конвенция (2003): ч^. 11 „илентифрициране и дефиниране на различните елементи на нематериалното културно наслеАство, присъстващи на нейна територия, с участието на общности, групи и съответни неправителствени организации." 
културното наследство и инорормационното общество (член 14) И укрепване на културното развитие чрез използването на цифрови технологии. Поради тази причина от основно значение е $\Delta$ а се подобри разбирането на едектите на тези нови инструменти върху изграждането и илентичността на участващите общности в запазването на културното наслеАство.

Използването на Web 2.0 платорорми за Аигитално представяне на елементи на нематериалното културно наслелство дава нови възможности за популяризиране, виАимост и ново мислене за управление на познанието за нематериалното наследство (Santova, 2017). От своя страна ползването на Аигиталните инструменти носи неочаквани социални изменения свързани не само с общностите на практикуващите, но и на свьрзаните вьншни за общността заинтересовани страни или „общности по интереси“[Фиг. 1]. (Rossi, 2018).

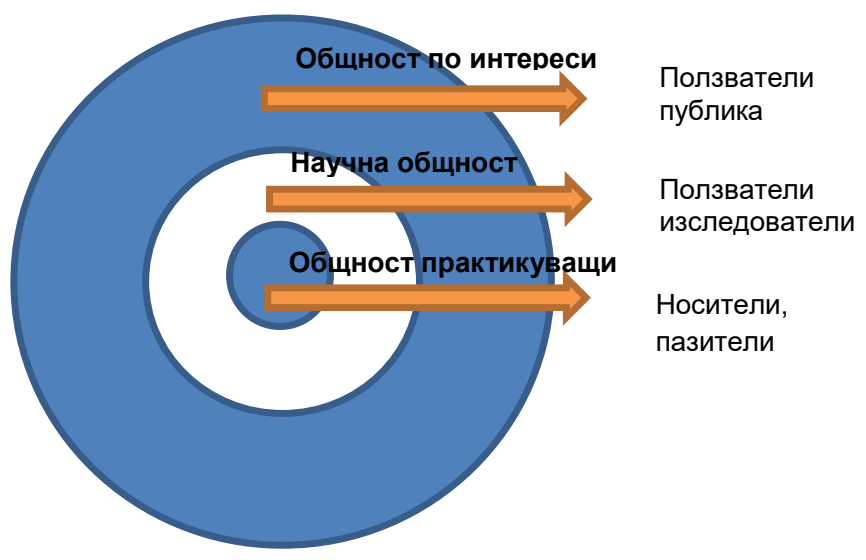

Фиг.1. Концентрична йерархична система на общностите

\section{METОАОЛОГИЯ НА ИЗСАЕАВАНЕТО}

За целта на изслеАването бяха обстойно проучени 65 фолклорни и многожанрови фрестивала, проведени във виртуална среАа. 
Проучени бяха и условия за участие и организационен статут на 46 фрестивала с бълещ периол на провеждане. За оценка и анализ на организационните Аейности са взети под внимание следните критерии:

1. Използване на Аигитални орорми на пред-подготовка популяризиране;

2. Обработка на Аанните на участниците;

3. Коректност и навременна комуникация;

4. Използване на Аигитални платорорми за провежлане;

5. Генериране на публика, обратна врьзка;

6. Начини на представяне на резултати;

7. Аигитален отпечатьк.

\section{ТИПОЛОГИЯ НА Е-ФЕСТИВАЛИТЕ С ФОАКАОРНА НАСОЧЕНОСТ}

При организационните процеси се наблюАават Ава основни по ХХоАа съобразно разбиранията и възможностите на организационните екипи. ЕАиният поАХоА се очертава с преАставителен характер, а Аругият с конкурсен характер. От своя страна фрестивалите с конкурсен характер могат $а$ а се разделят на строго специализирани и конкурси с отворен формат (K. Nikolov, G. Bogdanova, 2020).

\section{ПОАХОА C ПРЕАСТАВИТЕАЕН ХАРАКТЕP}

Е-фрестивалите с преАставителен характер ползват похвати близки АО същността на фрестивалите С насоченост за Аостьп Ао широка аудитория. Предварително изготвени видео записи от подбраните участниците в съответния фрестива^ се предоставят на организационния комитет, като в определената дата час се изльчва полбрания материал от виртуално студио. За изльчване на програмата се използват различни социални мрежи и платорорми за видео сполеляне. Като пример за проведен е-фрестивал с представителен характер е МежАународния фролк^орен фрестивал в Бразилия, който се сьстоя на 22 и 23 август 2020. На "сцените" на онлайн фрорума се представиха групи от 18 Аьржави. Най-изявените изпьлнители представиха фолклора на Румьния, Испания, Гърция, Чехия, Холандия, България, Бразилия, Гана, Аржентина, Чили, Южна Корея, Южна Афррика, Мексико, Колумбия и Венецуела. В рамките на фрестива^а са организирани и сьпьтстващи събития. 
Паралелните събития бяха насочени към: Отбелязване на 50 голини "Аен на Земята", „ЗасажАане на Аьрвото на мира", „Стьпки за мира", "Поглед на мира", „Ареха на мира“, „Възпоменателен печат в Пощата". Участниците се запознават с култура на различни страни, в проль^жение на Ава Ани, в комдрорта на Аома си и без $л а$ се налага $А а$

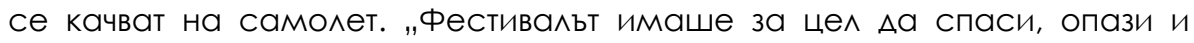
обедини народните култури. Осъществихме обмен с повече от 100 страни", казва Хелена Ауренцо, презилент на ABrasOFFA. Авата феествални концерта са наблюдавани от около 5000 зрители, [Фиг. 2] което за стандартен фролклорен фрестивал е също голямо постижение.

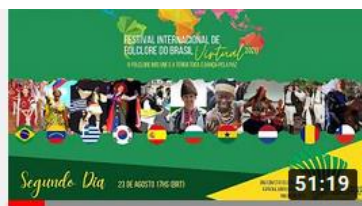

Festival Internacional de Folclore do Brasil Virtual...

1,9 хил. показвания · преди 6 месеца

Субтитри

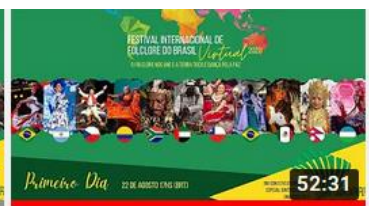

Festival Internacional de Folclore do Brasil Virtual...

2,9 хил. показвания . преди 6 месеца

Субтитри

\section{Фиг.2. Вилео прелставяне на фестивалната програма}

Може $а$ а се отбележи, че фрестивалната програма може $а$ бъ $л е$ наблюдавана не само по време на провеждането, а и в следващи периоли чрез създаления Аигитален отпечатьк от проведеното събитие. ${ }^{4}$ Като се има преАвиА, че фрестивальт се провежАа от 28 години и за пьрви пьт Аостьп Ао преАставянето на групите може $а$ а се осьществи не само от местната публика, а и от зрители от цял свят, то усилията на организационния комитет в тази посока са напьлно заслужени.

ПOАХOA C KOHKУPCEH XАPAKTEP

Строго специализиран конкурс

Фестивалите с конкурсен характер също претьрпяват трансорормации, прилагайки нова орорма на провежАане. Строго

\footnotetext{
${ }^{4}$ ABrasOFFA - YouTube, [https://www.youtube.com/c/ABrasOFFA/videos] (Viewed at 12-03-2021)
} 
специализираните конкурси стандартно не се ралват на голяма посещаемост от зрители поради еАнообразието на представяните изпьлнения.

Обикновен зрител трудно може $л а$ бьла зальржан при провежлането на специализиран конкурс за изпьлнители на гьлулка, акордеон, гайда и други. Обикновено зрителите за подобен рол конкурси са журиращата комисия, на която се налага понякога в продьлжение на Ава или три Ани Аа оценява стотиците изпьлнитеАни записани за участие. Обикновено в края на специализираните конкурси се организира гала концерт на ^ауреатите и обявяване на класирането, на който е възможно присъствието в залата на публика $А$ е увеличено многократно. Организирането на подобни мероприятия във виртуална среда носи своите бонуси и вече може $а$ а се каже предпочитания както от участници, така и от журиращата комисия. В Анешно време вече е възможно $а$ а се участва на фестивал с конкурсен характер, както то местно, национално, така и международно значение. Тежестта на конкурса зависи, както от нивото на журиращата комисия, организационния статус на организатора, така и от популярността на провежАания конкурс. Вече има изградени няколко външни Аигитални платформи за електронно оценяване, което $А$ ава възможност на експерти и изтькнати културни Аейци $А$ участват в различни журиращи комисии без да напускат рамките на своя Аом. Сбльсквайки се с проблемите на всички журиращи комисии при оценяването на изпьлнителите в реална среда, то при оценяването във виртуална среда е значително улеснено като в продьлжение от няколко АНи всеки член има възможност Аа преглежАа по няколко пьти всяко от изпьлненията на участника и дале коректно мнение при оценяването. [Фиг. 3]. 

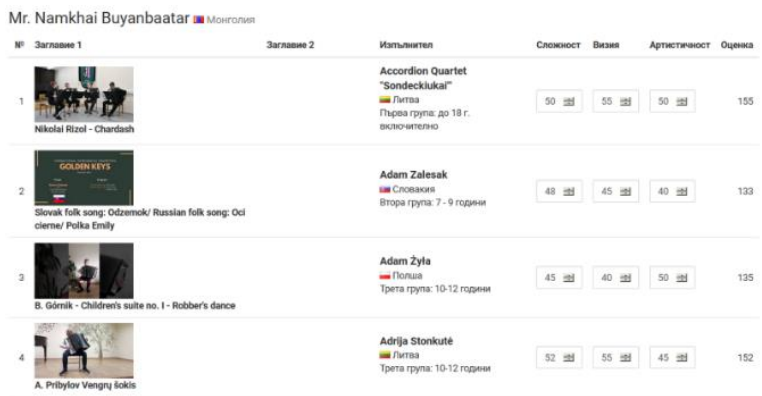

Фиг.3. Електронен оценителен Аист

От страна на участниците положителното е, че всеки може $\Delta а$ направи многократни записи на изпьлнението и може $А$ представи найАобрия вариант. Обзор на Аигитални инструменти за запис, обработка и платорорми за належАни връзки е предоставен от Университета в ОксорорА 5 . Възможността да гласуване от страна на публика е приом способстващ за увеличаване на зрителската аудитория. Някои от конкурсите Аостигат Ао наА 25000 гласуваня.[Фиг. 4].

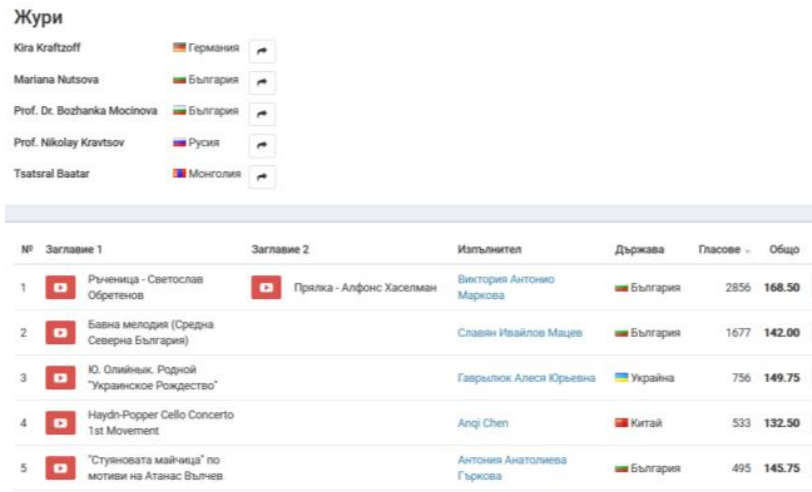

Фиг.4. Електронно преАставяне на крайно к^асиране

Примери за строго специализиран конкурс са: Международния вокален конкурс „Златен глас"6, на който се представиха хорове, вокални групи и инАивиАуаАни изпьлнитеАи от България, Русия, Аитва,

\footnotetext{
5 Faculty of Music, https://www.music.ox.ac.uk/about/facilities/music-technology/toolsfor-collaboration-and-recording-during-the-covid-19-crisis/ (Viewed at 26-03-2021) ${ }^{6}$ Межлународен инструментален.... https://eaff.eu/bg/championships/959-2901international-instrumental-competition-golden-strings-online (Viewed at 26-03-2021)
} 
Аатвия, Румъния, Беларус, Украйна, САЩ, Армения, Израел, Република Корея и Тайван (провинция на Китай). МежАународния инструментален конкурс „ЗАатни струни“7, на който се изявиха 64 изпьлнители от Китай, Аитва, Полша, САЩ, Русия, Украйна, Република МолАова, България, Ислямска република Иран, Малайзия, Узбекистан и Република Корея.

Межлународен инструментален конкурс "3латни клавиши"8, на който участваха 65 номинации от 9 Аьржави - България, Русия, Аитва, С^овакия, Полша, Босна и Херцеговина, Естония, Китай и ФинланАия. 720 участници се изявиха във II МежАународен онлайн танцов феестива^ "DANCE LINE"9. Виртуалното събитие се провеАе на 16 януари 2021 г., приветствайки артисти от 11 дьржави - Русия, Република Беларус, Казахстан, Аатвия, Иран, САЩ, Белгия, България, Национална република Ауганск, Малайзия и ИнАОНезия.

Може $\mathrm{a}$ се подчертае, че провежлането на конкурси във виртуална срела преАразполага организаторите на тези мероприятия $\Delta а$ полбират високо квалифицирани журиращи комисии. Пример в тази насока може $а$ п покажа именно за Межлународен инструментален конкурс "ЗАатни к^авиши", в който журиращата комисия имаше изкАючително висок статут. Председател на журито бе профр. Николай Кравцов - от Санктпетербургски Аьржавен институт за култура - Русия, КатеАра по фролклорно инструментално творчество към фракултета за изкуства, заслужи^ деятел на изкуството на Руската фредерация, Аействителен член на Межлународната акалемия по инорорматизация Кьм ООН; ^ауреат на "Златната Книга на Отечеството“. Членове на журиращия сьстав бяха: проор. Казис Стонкус - Аитва, Музикална Акалемия към Университета „Витаутас Велики", Ръководител на обучението по акорАеон, Президент на Аитовския национален съюз на акорАеонистите, Презилент на АкорАеонния съвет на Балтийските страни, член на Музикалния комитет към Международната

\footnotetext{
${ }_{7}$ Межлународен вокален конкурс..., https://eaff.eu/bg/championships/954-2865international-vocal-competition-golden-voice-online (Viewed at 26-03-2021)

8 Межлународен инструментален..., https://eaff.eu/bg/championships/1011-2811international-instrumental-competition-golden-keys-online (Viewed at 26-03-2021)

9 II International Online Dance Festival, https://eaff.eu/bg/festivals/969-2953-iiinternational-online-dance-festival-dance-line (Viewed at 26-03-2021)
} 
коноредерация на акордеонистите - Оорициален партньор на ЮНЕСКО; профр. Уен Куан - Китай, Аалиански колеж за изкуство, ръководител на учебната и изследователската дейност по акордеон. Оценителната комисия бе представена и от Веселин Ажанкардашлийски - България Аългогодишен преподавател по акорАеон в СМУ „Христина Моророва“ гр. Стара Загора, съавтор на учебни програми за обучение по акорлеон; носител на ОрАен „Кири^ и Метолий“ Първа степен и Награда на Министерството на културата на Република България „ЗАатен век - печат на цар Симеон"; г-н Намсрай Буянбаатар - Монголия.

Изпьлнител в Народния оркестьр към Колежа за музика и танци и негов Аиригент. От 2006 - ГАавен Аиригент на Големия Национален театьр за народна музика и танци. Заслужи^ артист на Монголия.

Интернет базираната платдрорма на Европейската асоциация на фолклорните фестивали - ЕАФФ преАоставя обратна врьзка за сполеляне на впечатления и оценаване на организационните процеси виАени от страна на участниците в събитията. Събраната база от оценки и мнения се визуализира в оценителна таблица, като се осъществяват релации с Аостьп от аАминистративния панел на организационния екип и колективните членове на асоциацията. Сегмента за обратна връзка и оценка спомага организацията на събитието, съобразявайки се с конструктивните прелложения за полобряване на процесите и бълещо избягване на допуснати грешки или неточности. Представям няколко мнения относно конкурса Международен инструментален конкурс "З^атни к^авиши":

„International Instrumental Competition "GOLDEN KEYS" - ONLINE was one of the best competitions we ever have took part. The information and answers about the competition was very fast and comfortable. "GOLDEN KEYS" competiton was very good motivation for young musicians and we are very interested to take part such competitions like "GOLDEN KEYS" ONLINE in the future.

Best wishes to organizers, Folk-music ensemble "Cantelo" Pärnu Art's School ESTONIA

I just wanted to thank you for organized International Instrumental Competition "Golden Keys" in this difficulttime for everyone. It was wonderful competition on a high level. Best wishes, Lidia Sawicka Samorzadowa Szkoła 
Muzyczna I Stopnia z Polskim i Litewskim Językiem Nauczania w Puńsku, Poland

I proud to participate in contest, we are very happy and want to cooperate in future.- Augustas Rimgaila III group - Siauliai music school number 1 (Šiauliy 1-oji muzikos mokykla), Lithuania

От анализа на обратната врьзка с участниците може $а$ с се направят конкретни изводи за полезността на поАходите на организационния комитет за провежАането на събитието във виртуална среда.

Е-КОНКУРСИ С ОТВОРЕН ФОРМАТ

Конкурсите с отворен фрормат Аават възможност за участие в различни жанрови категории на традиционното творчество. В тези конкурси е възможно Аа участват изпьлнителни на песни, танци и различни инструменти. Възможно е участието както на хорове, ансамбли, оркестри така и на малки фрормации и индивиАуални изпьлнители. Пример за еконкурс с отворен фрормат са: Световна купа по фролк^ор - Велико Търново 2021 - он^айн, Световен шампионат по фролк^ор "World folk 2020" ОНААЙН, ОНААЙН Фолк^орен феестива^ - конкурс "Asia Folk 2021". Оценяването по категории и жанрове също е във виртуална среда.

\section{Обявяване на резултати}

При обявяването на крайните резултати се наблюАават няколко способа. Аиректно обявяване чрез електронните пощи на участниците, като се изпращат Аип^омите и крайното класиране. Вилео обявяване е способ, при който чрез постмонтажна видеотехника се монтират вилео представянията на участниците в обща програма по категории и отАелен вилео ффилм за Аостигналите Ао най-високи оценки. Пример за вилео обявяване на резултатите на фестивал, които се публикуват чрез платорорма за вилео сполеляне е I. International ONLINE Competition and Festival of Music and Arts "COPENHAGEN STARS 202110

\footnotetext{
10 TheFestivalBridges...,

https://www.youtube.com/channel/UCs8A3Q6DtjXST2RYk1CX9og (Viewed at 29-032021)
} 


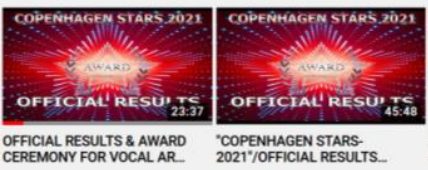

$2021 \%$ OFFICIAL RESULTS

$12 \mathrm{~K}$ views $\cdot 1$ week age
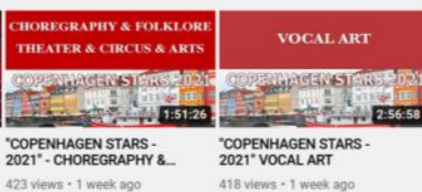

"COPENHAGEN STARS. 2021 " VOCAL ART 418 views -1 week agc

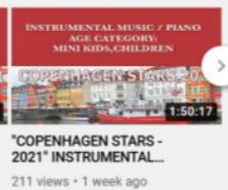

211 viens 1 meek age

\section{Фиг. 5 ВиАео обявяване на резултати чрез платформа за виАео споАеляне}

Аруг способ за обявяването на резултатите от конкурс е чрез пряко изльчване на церемонията в социални мрежи или платорорма за вилео сполеляне.

Пример за такъв способ е фестива^а International Awards in the Field of Performing Art "Folk-Star" - Online, 2 - 6 December 2020, St. Petersburg, Russia ${ }^{11}$. Подход за вк^ючване в церемонията по награждаване и на участниците е използването на платорорми за Аиректна комуникация като ZOOM, Meetings и Аруги. Пример за включване на участниците в церемонията можем да далем чрез фестивала-конкурс - Световна купа по фолккор - Велико Търново 2021 - онлайн.

\section{ИЗГРАЖААНЕ НА Е-ПРИАОЖЕНИЕ ЗА КОМБИНИРАН ПОАХОА}

ЗА ПРОВЕЖААНЕ НА ВИРТУААНИ ФЕСТИВААИ

C KOHKУPCEH XAPAKTEP

Слел анализ на типологията и способите на провежлане на виртуални фестивали в колаборация С програмния екип на Европейската асоциация на фолклорните феестивали - ЕАФф (EAFF, 2021) се внеАри комбиниран подход на провеждане, който съчетава и трите представени способа използвайки платформа за срещи и едновременно излъчване на живо в платдрорма за видео сполеляне, кьдето изготвения материал остава на разположение за слелващо ползване. Чрез планирането и осъществяването на електронната п^аторорма и комбинирането на различни комуникационни технологии се осъществи налграждане на съществуващите до момента принципи на работа и способи.

\footnotetext{
11 Folk Star-2020. LIVE..., https://www.youtube.com/watch? $\mathrm{v}=\mathrm{nx}$ 4T_jolJI\&amp\%3Bfeature=youtu.be (Viewed at 26-03-2021)
} 


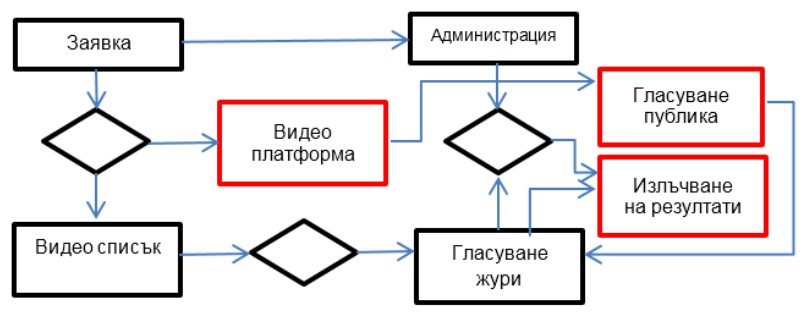

\section{ФИГ. 6. ER /ENTITY RELATIONS/ MOAEA HA ОРГАНИЗАЦИОННА СТРУКTУРА}

На [Фиг. 6] е изобразен организационния модел, като всяка модална връзка е свързана с релационна база от Аанни тип „Много от много" като част от основната база от $А$ анни на Web 2.0 платфрорма.

Платорормата е базирана на PHP 7.3.2 (The PHP Group, 2020) с обектно програмиране (ООР) използваща CakePHP MVC Framework (Cake Software Foundation, Inc., 2020), както и Аинамична структура на базите от $\triangle$ анни (DSDB) MySQL, Визуализацията e code Bootstrap HTML/ CSS Framework (Bootstrap, 2020), jQuery Ja-vaScript Library (The jQuery Foundation, 2020) Less CSS Preprocessor (core Less team, 2020), DomPDF Generator (GitHub, Inc., 2020). П^атфрормата работи на Linux операционна система (XenForo Ltd., 2020) и Apache web server (The Apache Software Foundation, 2020). Аопьлнителни положителни ефректи от представения комбиниран способ.

1. Реализирана вилео платорорма в структурна матрица на представения вилео материал;

2. Стимулиране, увеличаване и включване на публиката чрез възможност за гласуване;

3. Вк^ючване на участници и публика в заключителния етап на фестивала чрез външна видео платорорма и изльчване на церемонията в своболна платорорма за вилео споделяне с възможност за проследяващо наблюдение.

\section{ЗАКАЮЧЕНИЕ}

Аналитично представените подхоли за организиране и провежлане на виртуални събития с фролк^орна насоченост, са силно свьрзани с изграждане на Аигитални умения, както на участниците, така 
и на организационните екипи. Обстановката свьрзана с COVIDI9 инспирира бързото навлизане на Аигиталните комуникационни технологии в сорерата на организиране и провежлане на виртуални събития не само в сорерата на фестивалите, но и в провежлането на научни конфреренции, семинари и обучения, чрез специализирани платформи съчетани с различни социални мрежи, стрийминг технологии и платорорми за вилео споделяне. Порали множеството преимущества, споменати по-горе в Аок^ала, много от организационните екипи на фестивалите се полготвят за хибридизация на организационните практики.

НаблюАава се и електронизация не само на предварителната полготовка на мероприятията, но и в частта на провеждане и отразяване. Не на последно място може $а$ а се отбележи и създаването на детайлен Аигитален отпечатьк, който е възможно $а$ б бьле ползван не само като популяризиращ и трансмисионен инструмент, но и основа на бъдещи научни проучвания, чрез създаване на архивни видео бази за научно сьльржание и анализи. Провежлането на е-феестивали с фолклорна насоченост полпомага общностите в инорормационно обучителен п^ан, Аопринасят за увеличаване на Аигиталните умения, имат трансмисионно и популяризиращо значение и играят мотивираща роля за съзАаването на дигитален отпечатьк, Аокументирайки моментното състояние на $\Delta$ aАeH елемент.

\section{LITERATURE (АИTEPATYPA)}

Bootstrap. (2020). Bootstrap. (Currently v4.5.0. Code licensed MIT, docs CC BY 3.0.), https://getbootstrap.com/ (Viewed at 01-06-2021)

Cake Software Foundation, Inc. (2020). CakePHP. (Cake Software Foundation, Inc.), https://cakephp.org/ (Viewed at 01-06-2021)

core Less team. (2020). lesscss. (core Less team), http://lesscss.org/ (Viewed at 01-062021)

COUNCIL OF EUROPE. (2005). Framework Convention on the Value of Cultural Heritage for Society.

EAFF, E. A. (2021). European Association of Folklore Festivals - EAFF. (European Association of Folklore Festivals - EAFF), from www.eaff.eu (Viewed at 15-03-2021) 
GitHub, Inc. (2020). GitHub. (GitHub, Inc.), https://github.com/team (Viewed at 01-062021)

K. Nikolov, G. Bogdanova. (2020). RESEARCH AND APPROACHES TO THE TRAINING AND EXCHANGE OF NATIONAL TRADITIONS AND LIVING CULTURAL HERITAGE. EDULEARN20 (pp. 8660-8666). IATED.

Rossi, J. (2018). The Republic of Korea ICHpedia wiki and the creation of a new webbased community of practice through online participatory methodologies. MEMORIAMEDIA Review, Art.2(3).

Santova, M. (2017). Invites the Secretariat... Safeguarding of the Intengible Cultural Heritage Today: Synergies, Harmonies, Sustaigible Development. Safeguarding of the Cultural Heritage (pp. 21-29). Sofia, Bulgaria: Prof. Marin Drinov Publishing House of Bulgarian Academy of Science.

The Apache Software Foundation. (2020). apache.org. (The Apache Software Foundation), https://www.apache.org/ (Viewed at 01-06-2021)

The jQuery Foundation. (2020). jQuery License. (The jQuery Foundation. jQuery License), https://jquery.com/ (Viewed at 01-06-2021)

The PHP Group. (2020). PHP 7.2 (The PHP Group), https://www.php.net/releases/7_2_0.php (Viewed at 01-06-2021)

UNESCO. (1972). Convention concerning the Protection of the World Cultural and Natural Heritage.

UNESCO. (2003a). Convention for the Safeguarding of Intangible Cultural Heritage.

UNESCO. (2003b). Identifying and Inventorying Intangible Cultural Heritage.

UNESCO. (2004). Implementing the Convention for the Safeguarding of Intangible Cultural Heritage.

UNESCO. (2006). Report of the Expert Meeting on Community Involvement in Safeguarding Intangible Cultural Heritage.

XenForo Ltd. (2020). linux.org. (XenForo Ltd.), https://www.linux.org/ (Viewed at 01-062021)

KALOYAN NIKOLOV

PhD Student

https://orcid.org/0000-0002-2006-7072

Institute of Ethnology and Folklore Studies with Ethnographic Museum, Bulgarian Academy of Science

Sofia, Bulgaria 

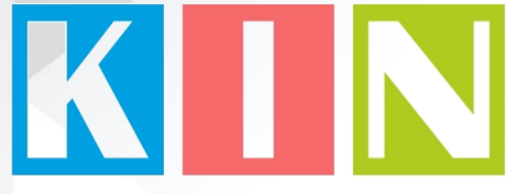

\section{ISSN: 2367-8038}

\section{Съставители \\ Петко Ст. Петков \\ Галина БогАанова}

Материалите в сборника са обект на авторско право. Разрешава се безвъзмезАното ползване на техни електронни/ хартиени копия само за мична употреба или обучение, при пьлно цитиране на текущата страница и слеА писмена Аек^арация от цитиращия за ^ипса на търговски намерения.

Научната поредица е регистрирана в НАЦИА С № 1209

() Авторски колектив, 2021

Техническо реАактори: Калина Сотирова-Вълкова Николай Ноев Паска^ Пиперков

\section{Editors}

Petko St. Petkov

Galina Bogdanova

This work is subject to copyright.

Open and free of charge use of digital/hard copies of publications is granted only for personal or educational use, with full citation of the current page, and after written declaration of the quoting side for notcommercial Intention.

Science series has been registered in NACID with No. 1209

() Authors` Group, 2021

Technical editors:

Kalina Sotirova-Valkova

Nikolay Noev

Paskal Piperkov

\section{ISSN: 2367-8038}

том 7, брой $1(10) / 2021$

vol. 7 , issue $1(10) / 2021$ 